\title{
Acute strongyloidiasis in a child recently returned from vacation in Cuba
}

\author{
Ajibola Alabi MD, Andrea K. Boggild MSc MD, Ari Bitnun MSc MD
}

Cite as: CMAJ 2017 November 20;189:E1416-20. doi: 10.1503/cmaj.170464

A seven-year-old girl born in Canada vacationed with her family at a beach resort in Santa Maria, Cuba, for eight days. Other than having atopic dermatitis intermittently managed with topical corticosteroids, she was healthy. During the trip, she spent most of her time at the beach, ate food provided at the resort and drank only bottled water. Her parents reported that she did not consume raw or undercooked meat, or seafood. She had no exposure to fresh water and remained well while in Cuba.

Four weeks after her return, the patient complained of feeling warm, and a nonproductive cough, nonbloody diarrhea three to four times per day and a rash had developed. Mild upper abdominal pain with no vomiting accompanied the diarrhea. About one week after symptom onset, she was taken to see her family physician who observed a pruritic, erythematous nonmigratory maculopapular rash on her upper trunk. The family physician ordered a complete blood cell count, and two stool samples to test for ova and parasites. The complete blood cell count was notable for high-grade peripheral eosinophilia (eosinophil count of 22.0 [normal $0.02-0.50$ ] $\times 10^{\circ} / \mathrm{L}$ ), which prompted referral to our centre. Both stool samples were negative for ova and parasites.

We examined the patient in our centre about two weeks after symptom onset. The truncal rash had resolved, but the diarrhea had persisted, and pruritus ani had developed. Her physical examination was notable for a dry, scaly erythematous rash that involved both of her elbows anteriorly, and skin excoriation and scratch marks on her buttocks and thighs. The remainder of her physical examination was unremarkable. Height and weight were appropriate for the patient's age.

A repeat complete blood cell count showed a hemoglobin level of 135 (normal 120-160) g/L, a total leukocyte count of 32.5 (normal 4.0-10.0) $\times 10^{9} / \mathrm{L}$ with an eosinophil count of 22 (normal $0.02-0.50) \times 10^{9} / \mathrm{L}$, and a platelet count of 425 (normal $150-$ $400) \times 10^{9} /$ L. A chest radiograph was normal. A stool sample tested negative for adenovirus 40/41; rotavirus; Norwalk virus; Salmonella spp.; Shigella spp.; Campylobacter jejuni, Campylobacter coli and Campylobacter lari; Yersina enterocolitica; enterotoxigenic Escherichia coli; Escherichia coli 0157; Shiga toxin producing E. coli; Vibrio cholerae; Clostridium difficile toxins A and B; Giardia lamblia; Entamoeba histolytica; and Cryptosporidium spp. (gastrointestinal pathogen multiplex polymerase chain reaction panel [xTAG Gastrointestinal Pathogen Panel, Luminex]). Three

\section{KEY POINTS}

- Strongyloidiasis should be considered in the differential diagnosis of peripheral blood eosinophilia in the returned traveller regardless of duration of stay in an endemic country.

- Consultation with a specialist in infectious diseases or clinician with expertise in travel and migration health is suggested when the diagnosis of strongyloidiasis is being considered.

- In select cases, it may be reasonable to make a presumptive diagnosis on clinical presentation alone, because results from stool examination and serologic testing can be negative.

- Treatment is recommended for all cases of strongyloidiasis to prevent lifelong infection and reduce the potential for lifethreatening hyperinfection during corticosteroid therapy or other forms of immunosuppression.

- In Canada, ivermectin, the drug of choice for the treatment of strongyloidiasis, can be accessed through a request to the Special Access Programme at Health Canada.

additional separately timed stool samples, collected between two and five weeks of symptom onset, were sent to the Public Health Ontario Laboratory. The first two tested negative for ova and parasites, but Strongyloides stercoralis rhabditiform larvae were found in the third sample. Serologic testing for S. stercoralis was nonreactive (optical density 0.10 [reactive, greater than 0.3 ; indeterminate, 0.2-0.3; nonreactive, less than 0.2]; Strongyloides IgG ELISA kit, SciMedx Corp.).

The patient was treated with two doses of ivermectin $(200 \mu \mathrm{g} /$ $\mathrm{kg}$ per dose) that were given two weeks apart. She had complete resolution of symptoms after the first dose. One month after treatment, her eosinophil count was $0.7 \times 10^{9} / \mathrm{L}$. Repeat serologic testing for $S$. stercoralis on samples drawn four weeks and six months after treatment were negative. Three stool samples taken after treatment were negative for ova and parasites. At sixmonth follow-up, the patient had no recurrence of symptoms.

\section{Discussion}

Strongyloides stercoralis is a skin-penetrating intestinal nematode with a complex life cycle (Figure 1 ). ${ }^{1}$ It is widely endemic throughout the tropics and subtropics (Figure 2), ${ }^{1}$ and travel to 
these regions places children, in particular, at risk of exposure, because they are more likely to play outdoors in contaminated soil without protection of their skin. Based on published data collated between 1984 and 2012, the prevalence of infection caused by S. stercoralis in Cuba ranges from $<0.01 \%$ to $0.2 \%{ }^{2}$ Our patient likely acquired the infection while on the beach where the family spent most of their time.

It is essential that clinicians are able to recognize the clinical syndrome of acute strongyloidiasis, because diagnostic confirmation is often difficult, particularly early in the course of infection. Symptoms associated with acute strongyloidiasis usually reflect larval migration from the time of skin penetration by filariform larvae to the production of eggs by mature female adults in the upper gastrointestinal tract (prepatent phase) and the early patent phase. ${ }^{3}$ Patients may report a localized pruritic rash at the site of skin penetration. After skin penetration, larvae enter an obligatory lung migration phase, during which time pulmonary symptoms, including cough dyspnea and wheezing, may occur. A complete blood cell count taken at the time of larval migration through the lungs and other host tissue will usually show highgrade peripheral eosinophilia, a finding that should prompt consideration of strongyloidiasis and other helminth infections
(Box 1). ${ }^{4}$ Diarrhea in the returned traveller should also lead to consideration of strongyloidiasis, but unlike viral, bacterial and protozoal causes, it has a long incubation period owing to a maturation phase of several weeks before reproductive adults are localized to the gut. In our case, the constellation of pruritic rash, gastrointestinal symptoms and eosinophilia preceded by a cough tailored the differential diagnosis to favour strongyloidiasis.

The definitive diagnosis of acute strongyloidiasis is challenging because of the insensitivity of standard diagnostic methods, particularly in early infection. ${ }^{5}$ Stool samples are categorically negative during the prepatent phase, which lasts 23-32 days (based on experimental studies of human infection). ${ }^{3}$ During the subsequent patent period, egg production by the adult female is intermittent and low; consequently, examination of multiple stool samples collected on different days and processed with laboratory concentration techniques may be required to show rhabditiform larvae in stool. ${ }^{5,6}$ Stool agar culture can enhance sensitivity, but it requires fresh stool, prolonged incubation and is potentially hazardous to laboratory personnel because of the cultivation of infectious filariform larvae. The absence of larvae from stool is insufficient to exclude infection. ${ }^{6} \mathrm{~A}$ case report of

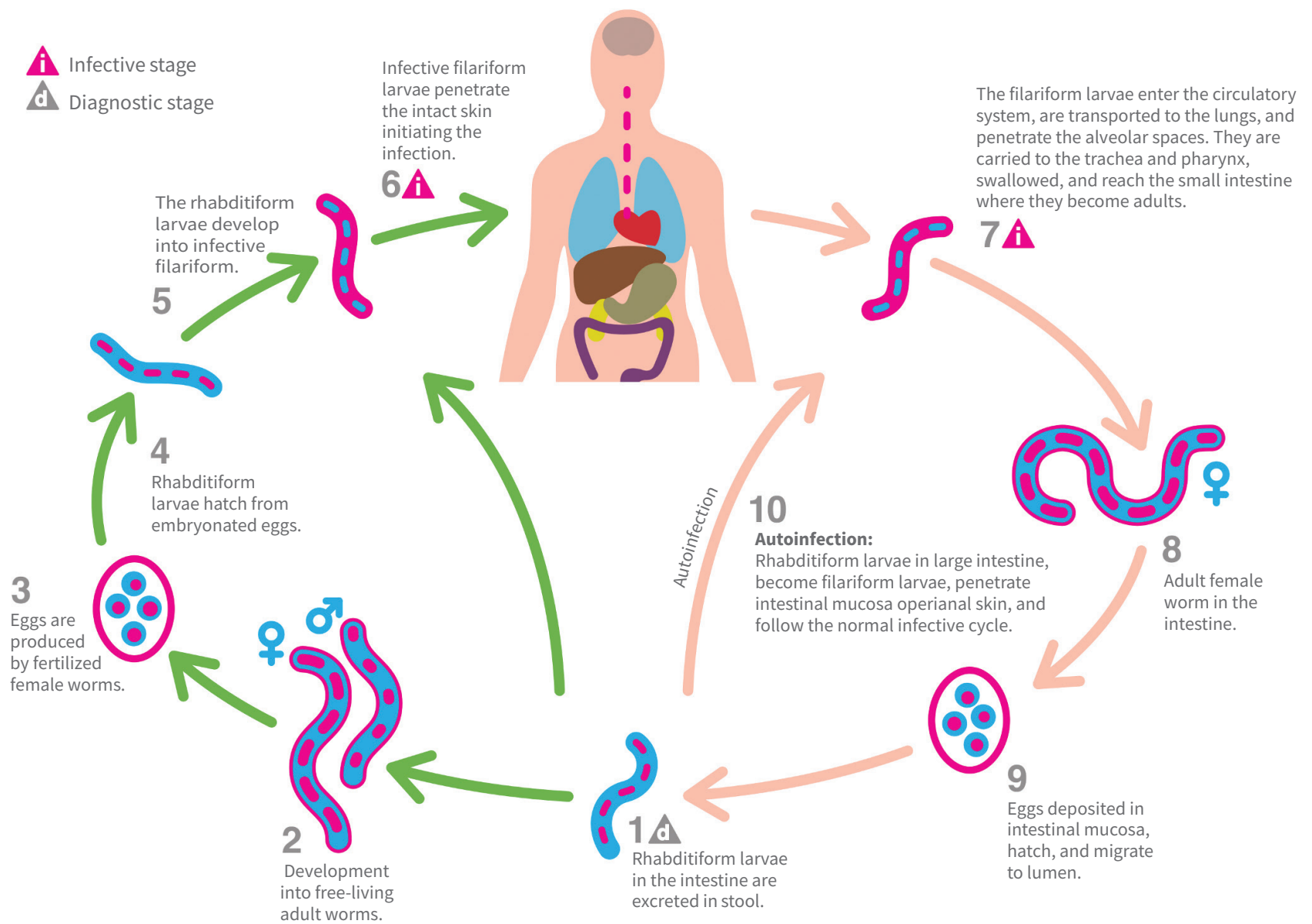

Figure 1: Life cycle of Strongyloides stercoralis. ${ }^{1}$ 
acute strongyloidiasis in two Italian tourists who returned from travel to Southeast Asia identified rhabiditiform larvae in the fifth sequential stool sample of one of the travellers but not in the other. ${ }^{7}$

Our patient's fifth stool sample was positive for larvae, reiterating the validity of examining multiple specimens. Because our patient was more than 28 days beyond last exposure and symptomatic with diarrhea and rash by the time of sampling, the first negative results were likely due to the limited sensitivity of stool examination and not because the stool samples were taken during the prepatent phase.

Serologic detection of antibodies to S. stercoralis also has performance limitations, although this technique is indicated for all suspected cases. ${ }^{5,8}$ In the returned traveller who is ill with acute strongyloidiasis, serologic testing has been shown to have a lower sensitivity than for chronic infection in migrants $(73 \% \mathrm{v}$. $98 \%$ ) and may be falsely negative. ${ }^{9}$ Several commercial enzyme immunoassays are available in North America, as well as inhouse assays at national reference centres. ${ }^{5}$ As with all serologic testing for helminth infections, specificity is limited and crossreactions may occur in patients with filariasis and other helminth infections.

Strongyloides is unique among the nematodes in that autoinfection can occur when larvae emerge from eggs and mature into the infectious filariform form within the host gastrointestinal tract and penetrate the intestinal mucosa (internal autoinfection) or perianal skin (external autoinfection), leading to lifelong infection by the parasite. Our patient presented with larva currens, the characteristic rash of strongyloidiasis, which occurs on the buttocks, groin and trunk, and is caused by migrating filariform larvae during an autoinfective cycle. Given the ability of strongyloidiasis to infect the same host for decades and its propensity to lead to a potentially fatal hyperinfection syndrome in the setting of immunocompromise, ${ }^{8}$ treatment of strongyloidiasis upon diagnosis is imperative. Ivermectin is the drug of choice, with albendazole being a less effective alternative. ${ }^{8}$ Both are safe and well tolerated. Neither drug is licensed or marketed in Canada; they can be obtained through the Special Access Programme at Health Canada (www.canada.ca/en/ health-canada/services/drugs-health-products/special-access/drugs /special-access-request-form.html).

Because strongyloidiasis has the potential to be a lifelong infection until treated, even remote travel history is relevant. This point is particularly germane in that often travel history is collected only for periods not extending beyond the preceding two to three years. Thus, parents should be asked specifically about remote travel of their children, because they may not deem such travel consequential.

The duration of travel that should prompt screening is controversial. ${ }^{10}$ The Canadian national guideline on the prevention, assessment and management of disseminated strongyloidiasis ${ }^{8}$ recommends that a cumulative exposure of six months should trigger screening in those at epidemiologic and clinical risk of

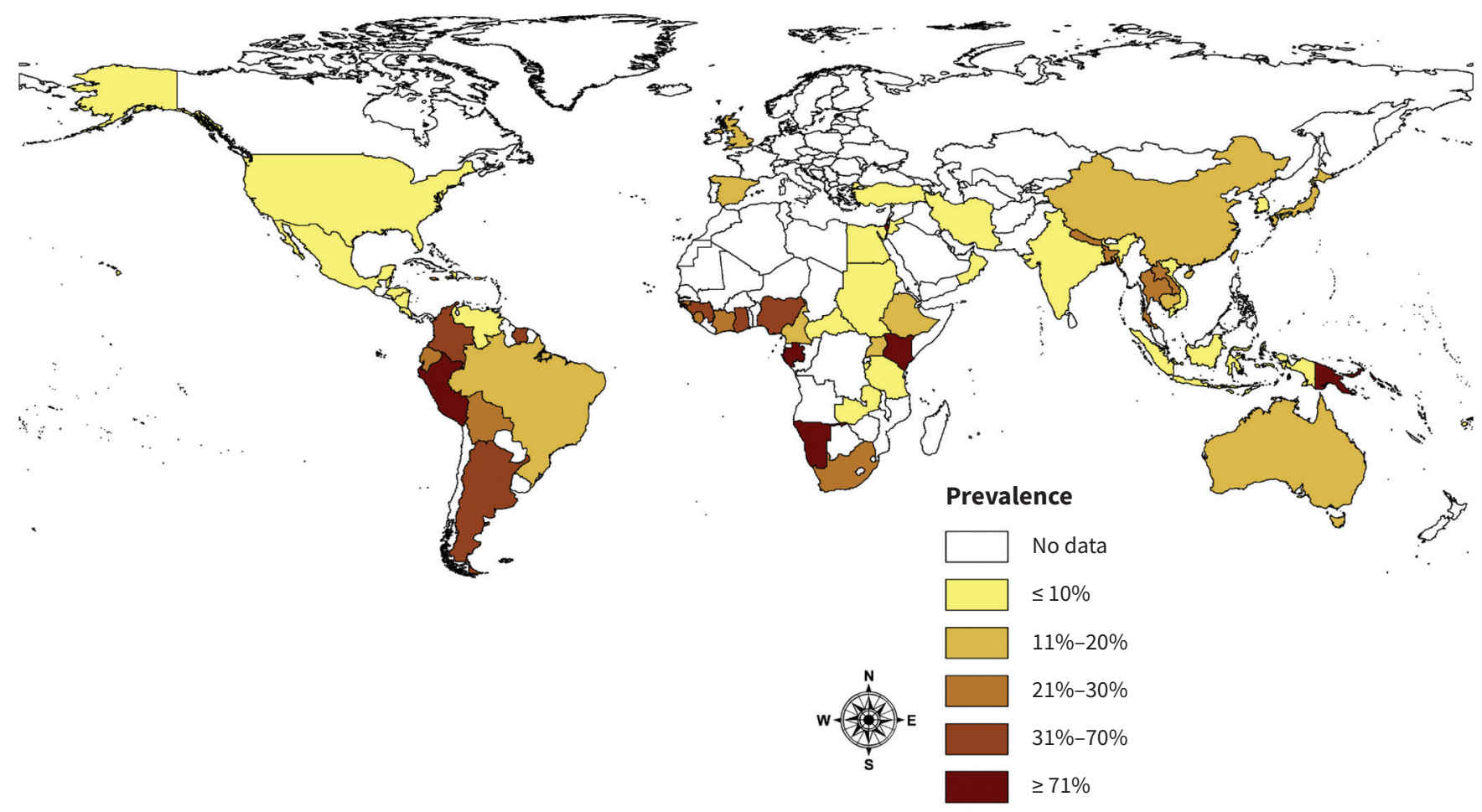

Figure 2: Prevalence of Strongyloides stercoralis infection by country. ${ }^{1}$ 
Box 1: Selected infectious causes of travel-related high-grade eosinophilia and associated clinical features*,$\dagger$

\begin{tabular}{|c|c|c|c|c|c|}
\hline Disease or pathogen & Geography & Relevant exposure & $\begin{array}{l}\text { Incubation } \\
\text { period }\end{array}$ & $\begin{array}{l}\text { Selected clinical } \\
\text { manifestations } \ddagger\end{array}$ & Laboratory diagnosis \\
\hline Ascariasis§ & Worldwide & Fecal-oral & $3-9 d$ & $\begin{array}{l}\text { Löeffler syndrome with } \\
\text { cough, dyspnea, wheeze, } \\
\text { chest discomfort, fever; } \\
\text { urticarial rash }\end{array}$ & Stool O\&P \\
\hline Hookworm§,ף & Worldwide & $\begin{array}{l}\text { Skin exposure to } \\
\text { contaminated soil }\end{array}$ & $8-21 d$ & $\begin{array}{l}\text { Löeffler syndrome with } \\
\text { cough, dyspnea, wheeze, } \\
\text { chest discomfort, fever; } \\
\text { pruritic maculopapular } \\
\text { eruption at site of larval } \\
\text { penetration }\end{array}$ & Stool O\&P \\
\hline Paragonimiasis & $\begin{array}{c}\text { Tropics/ } \\
\text { subtropics**}\end{array}$ & $\begin{array}{l}\text { Ingesting undercooked } \\
\text { crab or crayfish }\end{array}$ & $\begin{array}{l}\text { Several } \\
\text { months }\end{array}$ & $\begin{array}{l}\text { Cough, chest pain, } \\
\text { hemoptysis, rust-coloured } \\
\text { sputum, urticarial rash }\end{array}$ & $\begin{array}{l}\text { Sputum/stool O\&P, } \\
\text { serologic testing }\end{array}$ \\
\hline Schistosomiasis & $\begin{array}{c}\text { Tropics/ } \\
\text { subtropics }^{\star *}\end{array}$ & Fresh water exposure & $3-4 \mathrm{wk}$ & $\begin{array}{l}\text { Often asymptomatic; } \\
\text { Katayama fever with fever, } \\
\text { urticaria and angioedema, } \\
\text { chills, myalgia, arthralgia, } \\
\text { dry cough, diarrhea, } \\
\text { abdominal pain, headache }\end{array}$ & $\begin{array}{l}\text { Stool/urine O\&P, } \\
\text { serologic testing }\end{array}$ \\
\hline Strongyloidiasis§ & $\begin{array}{l}\text { Tropics/ } \\
\text { subtropics }\end{array}$ & $\begin{array}{l}\text { Skin exposure to fecally } \\
\text { contaminated soil }\end{array}$ & $23-32 d$ & $\begin{array}{l}\text { Löeffler syndrome with } \\
\text { cough, dyspnea, wheeze, } \\
\text { chest discomfort, fever; } \\
\text { pruritic maculopapular } \\
\text { eruption at site of larval } \\
\text { penetration, larva currens; } \\
\text { diarrhea }\end{array}$ & $\begin{array}{c}\text { Stool O\&P, serologic } \\
\text { testingt† }\end{array}$ \\
\hline Toxocariasis & Worldwide & $\begin{array}{l}\text { Fecal-oral, ingesting } \\
\text { undercooked organ } \\
\text { meat }\end{array}$ & $\begin{array}{l}\text { Weeks or } \\
\text { months }\end{array}$ & $\begin{array}{l}\text { Often asymptomatic; fever, } \\
\text { hepatitis, pneumonitis, } \\
\text { urticarial rash }\end{array}$ & $\begin{array}{l}\text { Serologic testing, tissue } \\
\text { biopsy }\end{array}$ \\
\hline Trichinosis & Worldwide & $\begin{array}{l}\text { Ingesting undercooked } \\
\text { meatł‡ }\end{array}$ & $7-30 d$ & $\begin{array}{l}\text { Often asymptomatic; } \\
\text { muscle pain tenderness } \\
\text { and swelling, elevated } \\
\text { creatine kinase, periorbital } \\
\text { edema, conjunctival } \\
\text { hemorrhages }\end{array}$ & $\begin{array}{l}\text { Serologic testing, } \\
\text { muscle biopsy }\end{array}$ \\
\hline \multicolumn{6}{|c|}{ 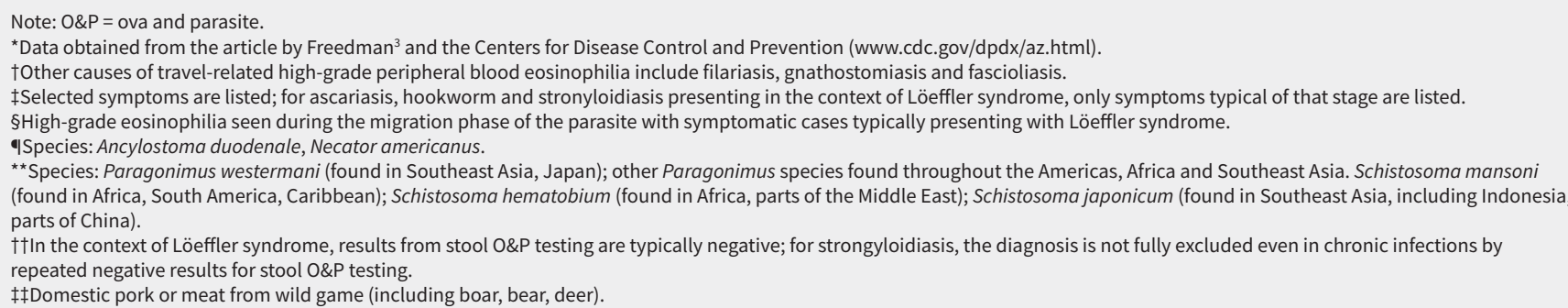 } \\
\hline
\end{tabular}

disease. However, there have been several case reports describing strongyloidiasis acquired by short-term travellers, ${ }^{7,11}$ and, as illustrated by our case, it is prudent to consider this diagnosis in a short-term traveller with a clinically compatible illness.

\section{Conclusion}

Strongyloidiasis should be considered in children returning from endemic regions with compatible symptomatology regardless of travel duration. Diagnosis is complicated by the limited sensitivity of serologic testing in the acute phase, absence of larval output during the prepatent phase and typically low organism burden in stool during the patent phase. Examination of multiple stool samples may be required to confirm the diagnosis. Because of the inherent difficulties in diagnosis and potential long-term consequences of strongyloidiasis, consultation with a specialist in infectious diseases or clinician with expertise in travel and migration health is suggested when the diagnosis is being considered. Empiric treatment should be considered in children with a compatible clinical syndrome even in the absence of microbiological proof of infection. 


\section{References}

1. Schär F, Trostdorf U, Giardina F, et al. Strongyloides stercoralis: global distribution and risk factors. PLoS Negl Trop Dis 2013;7:e2288.

2. Ketzis JK, Conan A. Estimating occurrence of Strongyloides stercoralis in the Caribbean island countries: implications for monitoring and control. Acta Trop 2017;171:90-5

3. Freedman DO. Experimental infection of human subjects with Strongyloides species. Rev Infect Dis 1991;13:1221-6.

4. O'Connell EM, Nutman TB. Eosinophilia in infectious diseases. Immunol Allergy Clin North Am 2015;35:493-522.

5. Dong MD, Karsenti N, Lau R, et al. Strongyloidiasis in Ontario: performance of diagnostic tests over a 14-month period. Travel Med Infect Dis 2016;14:625-9.

6. Sato Y, Kobayashi J, Toma H. Shiroma Efficacy of stool examination for detection of Strongyloides infection. Am J Trop Med Hyg 1995;53:248-50.

7. Angheben A, Mistretta M, Gobbo M, et al. Acute strongyloidiasis in Italian tourists returning from Southeast Asia. J Travel Med 2011;18:138-40.

8. Boggild AK, Libman M, Greenaway C, et al. CATMAT statement on disseminated strongyloidiasis: prevention, assessment and management guidelines. Can Commun Dis Rep 2016;42:12-9.

9. Sudarshi S, Stumpfle R, Armstrong M, et al. Clinical presentation and diagnostic sensitivity of laboratory tests for Strongyloides stercoralis in travellers compared with immigrants in a non-endemic country. Trop Med Int Health 2003; 8:728-32.

10. Baaten GG, Sonder GJ, van Gool T, et al. Travel-related schistosomiasis, strongyloidiasis, filariasis, and toxocariasis: the risk of infection and the diagnostic relevance of blood eosinophilia. BMC Infect Dis 2011;11:84.

11. Bailey KE, Danylo A, Boggild AK. Chronic larva currens following tourist travel to the Gambia and Southeast Asia over 20 years ago. J Cutan Med Surg 2015; 19:412-5.
Competing interests: None declared.

This article has been peer reviewed.

The authors have obtained patient consent.

Affiliations: Division of Infectious Diseases (Alabi, Bitnun), The Hospital for Sick Children; Tropical Disease Unit, Division of Infectious Diseases, Department of Medicine (Boggild), Toronto General Hospital, University Health Network; Department of Medicine (Boggild) and Department of Paediatrics (Bitnun), University of Toronto; Public Health Ontario Laboratories (Boggild), Toronto, Ont.

Contributors: Andrea Boggild and Ari Bitnun conceived the report and contributed equally to literature review, critical appraisal and writing of the manuscript. Ajibola Alabi contributed to literature review and was primarily responsible for writing the manuscript. All of the authors revised the manuscript critically for important intellectual content, gave final approval to the version to be published and agreed to be accountable for all aspects of the work.

Correspondence to: Ari Bitnun, ari.bitnun@sickkids.ca

The section Cases presents brief case reports that convey clear, practical lessons. Preference is given to common presentations of important rare conditions, and important unusual presentations of common problems. Articles start with a case presentation (500 words maximum), and a discussion of the underlying condition follows (1000 words maximum). Visual elements (e.g., tables of the differential diagnosis, clinical features or diagnostic approach) are encouraged. Consent from patients for publication of their story is a necessity. See information for authors at www.cmaj.ca. 